\title{
Rethinking Sanctions Efficiency
}

\section{Evidence from 205 Cases of the U.S. Government Enforcement Actions against Business}

\author{
Ivan N. Timofeev
}

\section{Abstract}

The article revisits the issue of economic sanctions efficiency. It concentrates on changes in business behavior when it is affected by governmental enforcement actions. The empirical groundwork is composed of 205 cases of U.S. governmental investigations vis a vis business in 2009-2019. The article tests two major hypotheses. The first one is about the measure of rationality of business when it violates existing sanctions regulations. The second one is about changes in business behavior during and after the investigation. Descriptive statistics shows that violations are rather not planned in advance. Reckless behavior is much more frequent than willful one. However, the data confirm the hypothesis about the transformation of business behavior during and after the OFAC investigation. This is an indicator of the high efficiency of

\footnotetext{
Ivan N. Timofeev, Ph.D. (Political Science)

MGIMO University, Moscow, Russia

Associate Professor;

Russian International Affairs Council, Moscow, Russia

Program Director
}

SPIN-RSCI: 3517-3084

Tel: +7(495)434-67-66

E-mail: itimofeev@russiancouncil.ru

Address: Office 324, 76 Vernadsky Prospect, Moscow 119454, Russia.

The research is supported by a grant of the Russian Science Foundation (Project 18-18-00439). 
sanctions against businesses as compared with relatively low efficiency vis a vis states.

Keywords: sanctions, U.S. Department of the Treasury, Office of Foreign Assets Control (OFAC), business, sanctions effectiveness, enforcement action, compliance.

\section{PROBLEM STATEMENT}

The question of whether economic sanctions are effective as a foreign policy tool has for a long time been central for the students of sanctions policy. Scholars have been rather skeptical about the utility of sanctions. Early research by Hufbauer et al. (1990) identified that only one-third of sanctions programs affected the behavior of a targeted state. Further critical reviews of their database showed even more pessimistic results, claiming that only $5 \%$ of sanctions were a success (Pape, 1997). Drezner (1999) coined the term 'sanctions paradox.' He concluded that moderate sanctions against allies are more effective than comprehensive restrictions against foes. Despite the mounting sanctions programs since the end of the Cold War and a significant improvement of restriction tools, there is still no confidence that the imposition of sanctions provides positive results (Rosenberg et al. 2016). Jaeger has recently pointed out that evaluations of sanctions effectiveness often include a significant degree of subjectivity (Jaeger 2018, p. 15). Darsey and Stulberg (2019) have stated that sanctions acquire different meanings as a concept in different national contexts.

Still, sanctions remain among the main foreign policy tools of Western countries. The U.S. has been the global leader in the use of sanctions and has imposed them more often than all other states and international organizations combined (Hufbauer et al., 2010, pp. $5,17)$. This may mean that despite controversial results, sanctions remain functional for one reason or another. To understand the towering demand for sanctions as a political tool one needs to revisit the concept of sanctions effectiveness as such. 
The "traditional" understanding of sanctions effectiveness implies an ability to change the behavior of a targeted state. By means of economic restrictions (trade embargos, financial bans, investment prohibitions, sectoral restrictions, etc.) the initiator or a coalition of initiators intends to force a targeted state to change its foreign or domestic policy. Coercion is the principal function of sanctions. Therefore, the effectiveness of restrictions is often linked to the change of a targeted state's foreign or domestic policy. Hufbauer et al. (1990, 2010) provided a benchmark for such an approach.

Coercion usually goes hand in hand with attempts to constrain the capabilities of a targeted state. Sanctions often aim to limit its military, technological or economic capabilities and punish it by inflicting economic damage. For instance, Neuenkirch and Neumeier (2015) compared the economic damage caused by U.S. and UN sanctions. Another important function is sending a signal to a targeted state. Restrictions may be symbolic in terms of damage, but they send a clear signal of discontent by the initiator. The signaling function has increasingly become of interest to scholars in recent years (see, for instance, Bapat et al., 2013). In terms of Drezner's 'sanctions paradox', signaling may be effective in relations with allies and partners.

Coercion, constraining and signaling are regarded as the functional core of sanctions and as a policy tool in contemporary research (Giumelli, 2016). These three functions have provided the background for numerous case studies, including those of Iran (Graef, 2013; Maloney, 2015; Nephew, 2018), North Korea (Kim, 2014; Haggard and Noland, 2017), Cuba (Spadoni, 2010), China (Cooper and Lorber, 2016), and Russia (Connolly, 2015, 2018; Kholodilin and Netsunaev, 2017, 2016; Fritsz et al., 2017; Crozet and Hinz, 2016; Moret et al., 2017).

There are also several other dimensions of sanctions effectiveness such as the impact of sanctions on human rights. The severe damage from a comprehensive embargo against the Iraqi population in 1991 fueled the search for ways to alleviate people's sufferings. Thus, the effectiveness of sanctions also implies their selective potential to affect the elites and certain individuals, not people in general. The terms 'targeted sanctions', 'smart sanctions' and 'surgical sanctions' 
emerged in the conceptual discourse in the 1990s and have become especially popular in the 21 st century (Drezner, 2015; Tourinho, 2015). Globalization and advances in financial intelligence provided the U.S. with an opportunity to use targeted measures on a completely different scale compared with the past practices (Zarate, 2013). However, there is much skepticism about the ability of 'smart sanctions' to avoid causing peoples' suffering and violation of human rights (Jazairi, 2015, 2018).

The success of sanctions may also mean internal changes in a targeted state. Here effectiveness may imply democratization or public revolt fueled by blocking the resources available to the political elite. However, the link between sanctions and democratization is not clear. Sanctions may even stimulate consolidation of the targeted regime instead of its collapse (Grauvogel and Soest, 2014), although some authors claim that the international community should continue to use sanctions in order to fight the threats to democratization (Marinov and Neli, 2015). Other scholars (e.g., Whang, 2011) have noted the use of sanctions for addressing internal issues in the initiator state.

All of these studies place emphasis on the state as a key actor. They follow a "state-centric" approach in a sense that they associate the success of sanctions with the behavior of a state, its capabilities and strategies. However, states are not the only target of sanctions. Private companies and business in general are targets too, especially if one takes into account the rise of 'smart sanctions' in recent years. Furthermore, there is the increasing use of 'secondary sanctions' which imply punishment of individuals and entities that are dealing with the sanctioned states or entities. Secondary restrictions imply "sanctions for violations of sanctions." U.S. regulators often implement secondary sanctions against American and foreign businesses. Many foreign businesses may be potentially subject to U.S. sanctions that involve restrictions in the use of the U.S. dollar as a key means of international payments. Secondary sanctions may be an important factor in affecting the behavior of businesses in their relations with a sanctioned state or entities. These sanctions apparently provide the U.S. government with another powerful leverage to increase the pressure on targeted states, compelling international businesses to abstain from cooperation with them. 
This article intends to analyze the efficiency of sanctions from a different angle compared to the "old-school" approach. Instead of looking at the change of the targeted state's behavior, it focuses on the use of secondary sanctions against business. It studies the impact of penalties imposed by the U.S. government on companies and individuals for commercial connections with targeted businesses and states, and the violations of U.S. sanctions programs. In other words, the study uses a "business-centric" approach to analyze sanctions efficiency instead of the "state-centric" one. Early and Preble (2018) have recently provided an example of such an approach.

The key issues of the research include patterns of violations of U.S. sanctions by businesses; strategies of business in dealing with the U.S. regulators; and the consequent impact of sanctions on businesses' behavior in terms of their attempts to further violate U.S. sanctions. The main question to answer is: Do penalties imposed by U.S. regulators (mostly by the U.S. Department of the Treasury) change the behavior of business in favor of compliance with the U.S.'s demands?

To answer the question above this paper tests two hypotheses. Hypothesis 1 postulates that business violates sanctions regimes in order to maximize its profits in general or to increase the profits of its branches or subsidiaries. In other words, business violates rules rationally. This assumption will be disproved if business demonstrates other patterns leading to violations.

Hypothesis 2 suggests that U.S. secondary sanctions against companies significantly affect their behavior and make them comply with U.S. regulations. Compliance is a rational strategy to minimize further financial and reputational losses caused by the regulators' punitive measures. Presumably, U.S. sanctions implemented in line with the "business-centric approach" may be much more effective compared with the "state-centric" sanctions. The effectiveness of sanctions against business is one of the reasons why sanctions are still functional and remain an important foreign policy tool. This assumption will be disproved if business does not generally change its behavior and continues violations regardless of the punitive measures imposed by U.S. regulators. 


\section{RESEARCH DESIGN}

To understand the correlation between U.S. regulators' policy and its impact on the behavior of targeted businesses we must first define and further operationalize what is exactly understood by 'policy' and 'behavior.' For the purposes of this paper 'policy' means certain actions by the U.S. governmental authorities to guarantee that business complies with existing sanctions programs and legislation. 'Behavior' means actions of business in terms of compliance with imposed sanctions. This research deals with cases when business violates imposed sanctions for one reason or another, while governmental regulators react with punitive measures in order to change the behavior of the violators.

The U.S. Department of the Treasury Office of Foreign Assets Control (OFAC) is a key governmental regulator, although in some cases other regulators take part in coercive actions. The Department of Justice, the Department of Commerce, the Federal Reserve System Board of Governors and other institutions may participate in investigations vis a vis American and foreign businesses. However, OFAC usually plays the leading role in relations with business.

Generally, OFAC implements two basic options to punish a violator. The first one is to include it in the SDN list which prohibits U.S. persons and entities under U.S. jurisdiction from dealing with a violator economically. The second option is to impose a financial penalty. This study analyzes the second measure only, because the SDN-list option does not leave many choices for a company or a person to change its behavior. Although the SDN-track is an interesting topic per se, it does not provide necessary argumentation to support or oppose my hypotheses. Financial penalties are apparently a more flexible tool. Its aim is not to exclude a violator from the international economy, but to change its behavior. Another critical factor for such a choice is the availability of empirical data. Although the SDN and other OFAC lists are publicly available, it is not always easy to identify the ways of a person's behavior prior to violation, and it is still harder to assess a person's behavior when he is already on the list. On the contrary, information about penalties provides enough evidence of the causes 
of violations, reaction of the U.S. regulator, and consequent behavior of a violator, whether it is an individual or a company.

The present study uses OFAC settlement agreements with companies, organizations and individuals as a major source. OFAC presents it in textual form. To transform this information into standardized data, the information was coded and transformed into a quantitative database. As a result, an OFAC Quantified Enforcement Database (OQED) has been created.

Coding and quantification are possible due to the similar structure of settlement agreements. Moreover, OFAC provides formal "Economic Sanctions Enforcement Guidelines" (Federal Register, 2009). This document defines financial penalties' calculation procedures. It also identifies aggravating and mitigating factors that affect the measure of punishment. Settlement agreements usually provide a schematic overview of the kind of violations, patterns of behavior prior to the violations, level of cooperation with OFAC by a company or person under investigation, and consequent measures taken to improve compliance with sanctions regulations. Enforcement guidelines and settlement agreements imply specific outcomes of actions taken by OFAC and by a person/company under investigation. Most of these outcomes can be formalized in a binary $1 \backslash 0$ code.

To test the hypotheses, the behavior of businesses has been operationalized in a number of variables.

Hypothesis 1 claims that a business acts rationally to break the sanctions rules. The main way to check this is to see whether OFAC identifies violations as willful or not. A willful violation would mean that a company had an initial plan to violate the regulations. Other variables include the following questions: Did the company attempt to conceal violations? Was it a regular practice or an isolated case? Was the company management aware of the violation? Did the company voluntarily disclose its violation to OFAC or other regulators?

OFAC qualifies violations as egregious or non-egregious. Willful violations almost automatically lead to an egregious status. However, egregious cases may not always be willful. Some of them represent reckless behavior, resulting, for instance, from ignorance 
about existing regulations. Reckless behavior does not mean that the company acted intentionally (rationally) to violate sanctions regulations. However, a company could, for instance, save resources necessary for the compliance program, external audit, personnel training, etc. An important variable for determining the degree of a company's investment to avoid violation of sanctions in advance is the existence of an effective compliance program as defined by OFAC in a settlement agreement. The absence of voluntary self-disclosure may signal reckless, although not willful, behavior. The abovementioned variables, such as management awareness about a violation, an attempt to conceal a violation, and the pattern of conduct, may also indicate that a company tries to rationally limit the damage from breaking the sanctions rules, while not informing the regulator about this.

In sum, the "rationality" to violate sanctions has two dimensions. The first one is willful behavior and the intention to maximize profit by violating the sanctions. The second one is reckless behavior, which may mean the intention to reduce compliance costs. Such a strategy may lead to mistakes in decision-making and to misbehavior. This is a situation where a short-term rationality causes losses in the long run.

A particular case does not fit into the hypothesis about the rational causes of misbehavior if violations were caused by inaccuracy, software malfunction, single (non-systematic) violations, etc. Usually, such violations are qualified by OFAC as non-egregious.

Hypothesis 2 requires operationalization of the change in the behavior of companies when affected by OFAC and other regulators. Voluntary self-disclosure is an important variable. However, its absence may not necessarily mean that a company intended to abstain from cooperation with OFAC. This may be the result of unawareness about a violation. However, other variables may be more illustrative. The first one is whether a company cooperates with an OFAC investigation in one way or another (by signing a tolling agreement, accurately providing documents, promptly responding to OFAC's requests, providing it with relevant information, reviewing other violations). The second variable is whether an entity takes remedial measures to improve the environment which caused the violation. These cases are 
recorded and treated as a specific variable for a particular measure: creation or improvement of a compliance program, personnel training, dismissal of managers responsible for violations, financial and human enforcement of a compliance program, external audits, preparation of compliance manuals, and due diligence of partners. Another important variable is the history of violations. OFAC regards a new violation as an aggravating factor if it has been committed within five years after the previous one. Repeated violations indicate that the long-term effect of OFAC's action is poor.

In other words, change of a company's behavior means that it cooperates with the investigation, takes remedial measures, and does not violate U.S. regulations again. However, the "history" variable should be treated carefully. Investigations may take seven to eight years. Existing data may simply omit cases of repeated violations which may emerge in the future.

Besides these variables, the OQED also includes statistics on base penalties, final penalties and statutory maximum penalties imposed by OFAC. It also includes national and sectoral classification of companies, the number of violations by a single person or entity, information about violated programs, duration of the investigation, and the participation of governmental regulators other than OFAC.

The database contains 73 variables. The analysis included the study of 205 OFAC enforcement cases from January 2009 to June 2019. The OFAC data provide settlement agreements up until 2003. However, the 2003-2008 documents significantly lack critical information and were excluded from the analysis. Early and Preble (2018) have made an analysis of the entire period, though with different research goals and assumptions.

\section{ANALYSIS \\ Preliminary observation}

The first important observation of the OQED descriptive statistics is the distribution of the national origin of individuals and entities under OFAC investigations. The majority of them are U.S. companies: 137 out of 205 cases. EU companies account for 40 cases. Other countries 
of origin include Switzerland (5), China (4), Japan (3), and 11 other nationals (Fig. 1).

Fig. 1. National Origin of Companies and Individuals under OFAC Investigations in 2009-2019

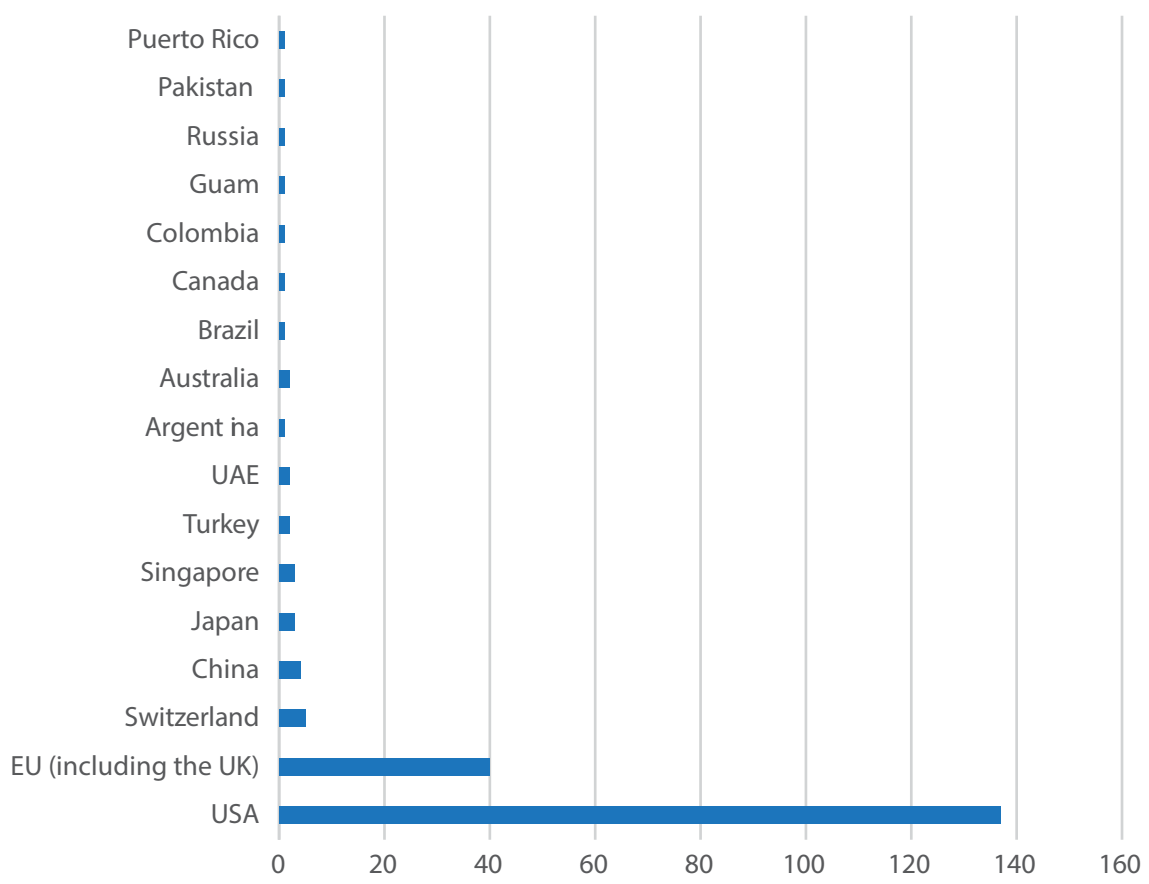

However, the U.S. skew should be misleading. American companies pay much less in penalties. They have agreed to pay $\$ 177.7$ million of the overall $\$ 5.63$ billion gathered by OFAC during a 10 -year period. This means that the share of U.S. companies is only $3.15 \%$. At the same time, EU companies have agreed to pay $\$ 4.67$ billion, which is $82 \%$ of the overall gains by OFAC in ten years. In other words, 40 EU companies have payed 26 times more than 137 U.S. entities and individuals combined (Fig. 2).

A majority of European payments were made by financial institutions. The analysis of sectoral distributions shows that the financial sector is a key contributor of payments to OFAC. Financial companies (mostly banks) account for 53 cases out of 205 . This is the most frequently sanctioned industry (Fig. 3). 


\section{Ivan N. Timofeev}

Fig. 2. Share of the U.S., the EU and China in the Overall Payments to OFAC in 2009-2019

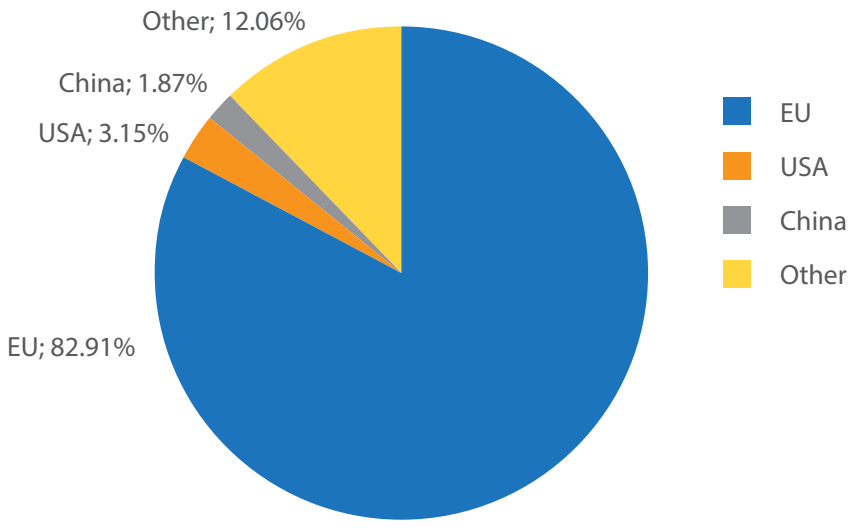

Fig. 3. Sectoral Origin of Businesses under OFAC Investigations in 2009-2019

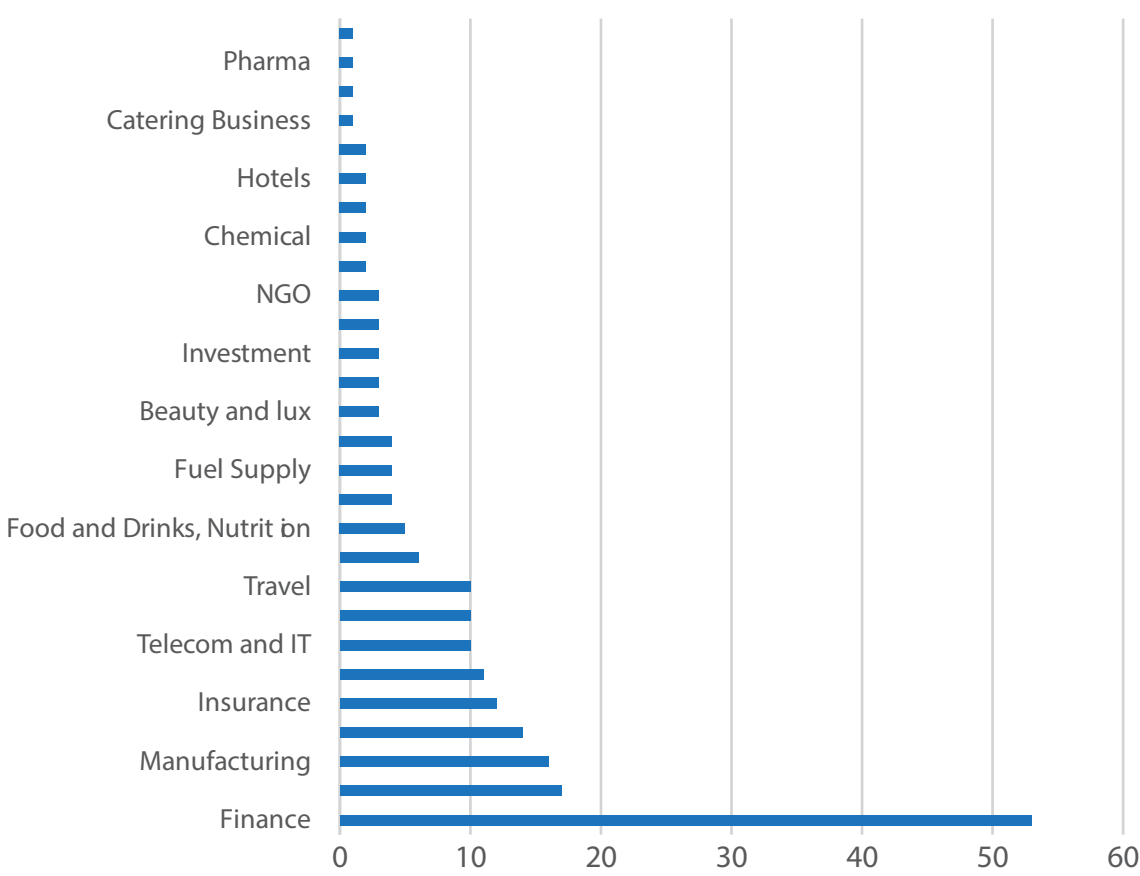

There are plenty of other sectors (oil and oil-service companies, telecoms, aerospace firms, insurance, investment, trade, manufacturing 
and other businesses). However, their representation is not as big as that of banks. At the same time, 53 financial companies pay $\$ 5.3$ billion in penalties of the total of $\$ 5.6$ billion gathered by OFAC. This is $93.4 \%$ of the total (Fig. 4) compared to $6.6 \%$ paid by 152 persons in other sectors.

Fig. 4. Share of the Financial Sector in the Overall Payments to OFAC in 2009-2019

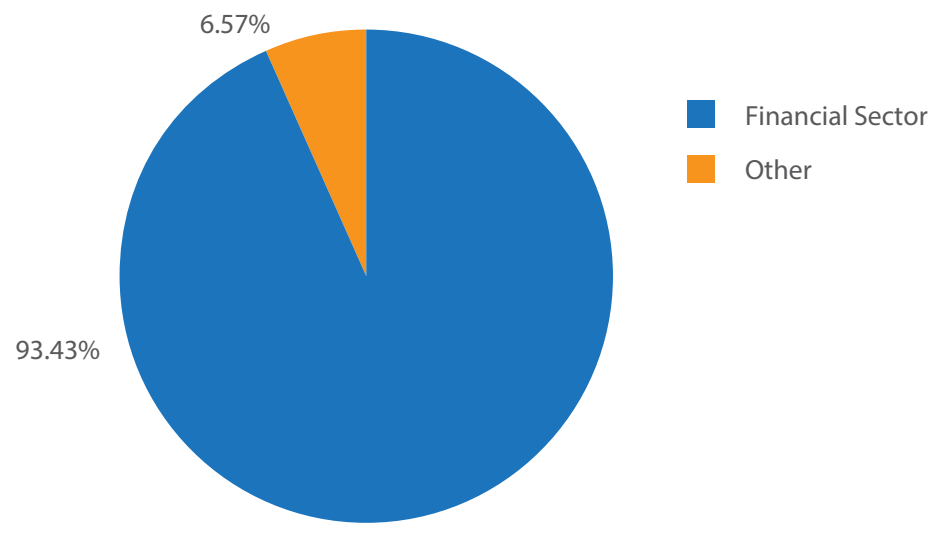

The financial sector represents another interesting skew. European banks are key contributors to OFAC's gains. I called it a "European paradox" and described it in my recent work (Timofeev, 2019). Of course, such distribution is hardly the result of deliberate discrimination of Europeans by the U.S. government. Banks make

Fig. 5. Number of Programs Violated by One Person

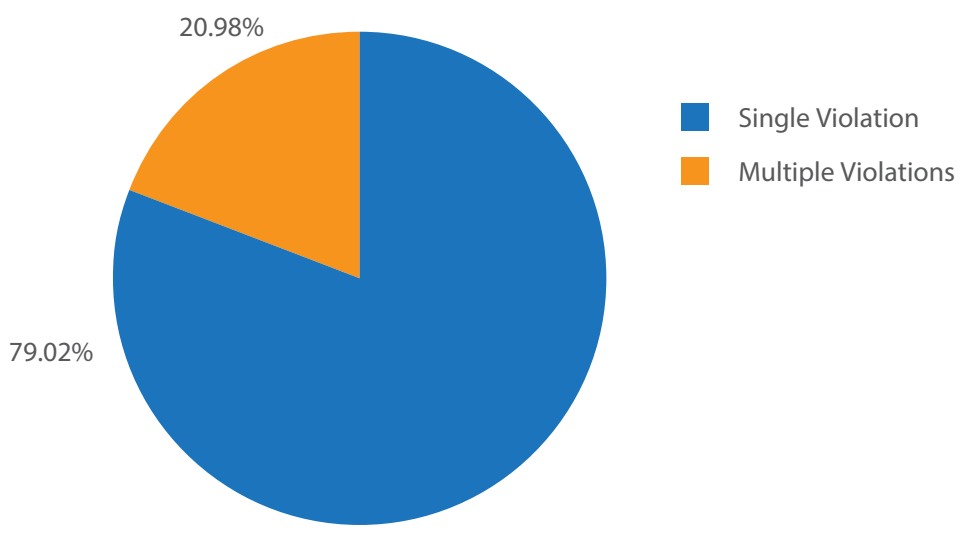


much more operations compared to other sectors and apparently are more likely to make mistakes or commit misconduct. The banks' vulnerability deserves a separate study.

Most persons under OFAC investigation violate only one sanctions program (79\%) (Fig. 5). In general, entities and individuals committed 312 violations in ten years. Iran is the most "popular" program violator: 107 cases out of 312 (Fig. 6). Cuba is the second one with 67. Such newest programs as the Ukrainian one accounts for only three violations. However, things may change in the future. The average duration of an investigation is 5.9 years. The mean value is presented in Fig. 6 with a median of six years. The longest duration is 14 years (starting with the year of the first violation and ending with a settlement agreement). The quickest took one year.

Fig. 6. Distribution of Program Violations

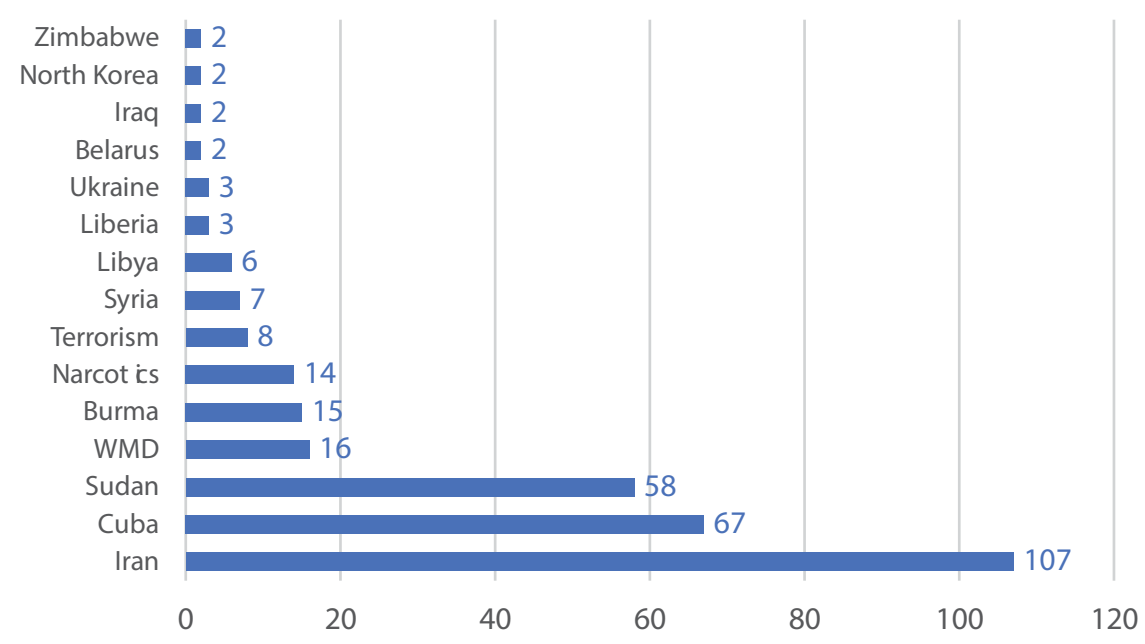

The average final penalty does not seem to be a representative indicator. The mean value is $\$ 27.8$ million, while the median is only $\$ 19,100$. This difference makes an average final payment a rather useless indicator. More interesting is the difference between base penalty and final penalty. In the majority of cases, final penalty is smaller than the base one. This will be important for testing the second hypothesis. 
The fact that OFAC makes discounts may mean that a business under investigation changes its behavior.

Last but not least for the introductory statistics is the fact that OFAC is the only regulator to run an investigation in 170 cases out of 205 (Fig. 7). In another 35 cases OFAC acted together with other regulators, such as the Department of Justice (22 cases), the Department of Commerce (13 cases), and the FRS Board of Governors (13 cases).

Fig. 7. Share of Cases Where OFAC Acted Alone or in Cooperation with Other Regulators

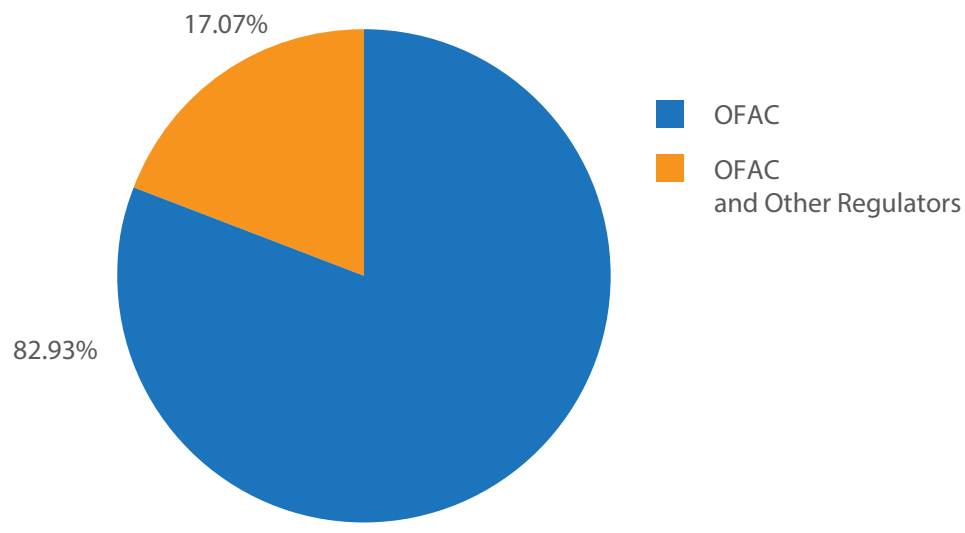

Fig. 8. Size of Business

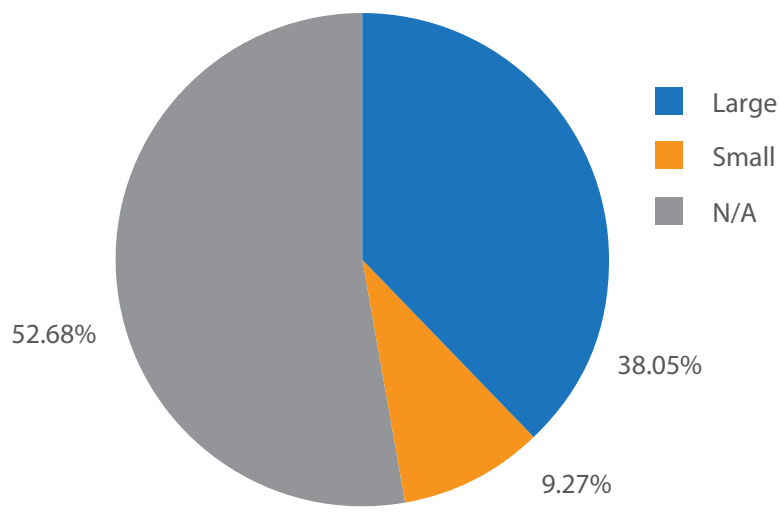

In terms of the size of companies (Figures 8-9), a majority of cases accounts for large (78) and sophisticated (81) companies, while 19 are small ones and 12 are not sophisticated. Other cases do not have an 


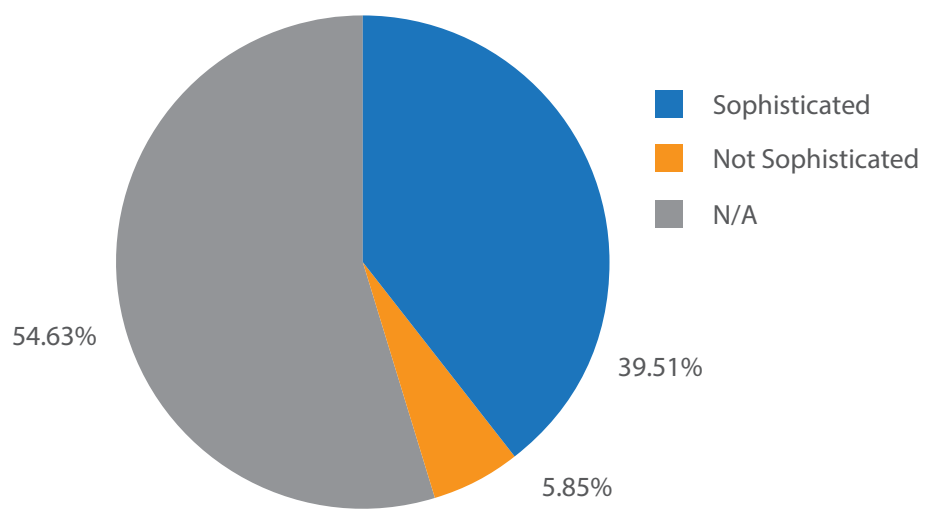

OFAC classification regarding their size or sophistication. Ten cases out of 205 account for individuals, and the other 195, for entities.

\section{TESTING HYPOTHESIS 1.}

The first important variable to test Hypothesis 1 is willfulness of a person's behavior to violate sanctions program. OFAC classified 32 of 205 cases as a willful violation, which accounts for $16 \%$ of all cases. Only in five cases OFAC assessed the behavior as unwilful. However, in most observations the cases were not classified, which may mean that OFAC does not consider willfulness to be the key factor in these cases. In other words, the share of willful violations is relatively small. On 14 occasions out of 32, willful violations went hand in hand with attempts to conceal them. In eight out of 32 violations a regular pattern of conduct was registered. On 19 occasions the senior management was aware of the violations. Thus, the data show that willful violations are usually not aggravated by attempts to conceal them, or by a regular conduct, or by involvement of senior managers. Still, such overlapping does occur, and these cases should be a matter of special research in the future. It is clear, however, that willful violations are usually of an egregious nature (22 of 32); only four of willful violations have been registered as non-egregious, and six are not classified. 
The analysis of reckless violations shows a different distribution. In 76 cases out of 205 reckless behavior was registered. On nine occasions the violations were both willful and reckless. Only 27 of 76 reckless violations are egregious, while 43 are non-egregious. This means that OFAC tends to assess reckless violations in a softer manner than willful ones. On 17 occasions out of 76 there was an attempt to conceal a reckless violation (this share is smaller than in the case of willful violations). The same is true about the regularity of the pattern of conduct (17 out of 76). At the same time, the senior management was aware of the violations in quite a considerable number of reckless violations: 41 out of 76 .

The adequacy of the compliance program prior to a violation is an interesting measure to compare willful and reckless violations. In general, the inadequacy of compliance is characteristic of a large portion of entities. OFAC classifies at least 86 cases out of 205 as inadequate in terms of compliance. Only nine cases are adequate. The remaining 110 cases are not classified. In 32 cases of willful violations 17 overlap with a fragile compliance program, while in the case of reckless violations 50 out of 76 indicate a similar problem. In other words, the data show that the inadequacy of the compliance program prior to violation is more characteristic of reckless rather than willful violations.

Another interesting measure to compare the two ways of behavior is voluntary self-disclosure of a violation by a company. In general, most of the persons under OFAC investigations do not disclose their violations voluntarily (132 cases out of 205). In 67 cases out of 205 there was a voluntary self-disclosure. Only 10 willful violations were disclosed volunarily, 20 were not, and two were not classified. In the case of reckless violations, 49 out of 76 cases were not disclosed volunarily, while 27 of out 76 cases were. In sum, both willful and reckless violations are usually not disclosed voluntarily.

The existing data do not provide enough evidence to support Hypothesis 1. Definitely, in some cases there is a rational (willful) plan to commit a violation, but the share of such occasions is small and accounts for only $16 \%$ of all cases. As for reckless violations, it 
is difficult to state whether they were rationally planned in advance. The fact that more than half of them (43 of 76) are non-egregious according to OFAC may mean that these violations are the result of inaccuracy, unintended actions, complex business environment, and other factors. In general, only 43 cases (willful, reckless, and other) out of 205 are egregious, while 106 are not, and the other 56 cases cannot be classified. The overall share of egregious cases is $21 \%$. This distribution rather disproves Hypothesis 1 than supports it. However, there is a relatively small share of companies which are clearly acting rationally to violate the rules.

It is difficult to say why both willful and reckless violators tend rather not to disclose their misconduct voluntarily. Clearly, there may be a rational reason for such a pattern of behavior. However, this may also be the result of unawareness. There is not enough data to identify the motivations, yet it is clear that a weak compliance program leads directly to higher vulnerability to violations, whether rational or not.

\section{TESTING HYPOTHESIS 2.}

To check the measure of compliance during OFAC investigations and afterwards three groups of variables were analyzed. The first one indicates whether individuals and entities cooperate with OFAC after their violations have become evident. In 144 cases out of 205 (70.2\%) there was at least one or more manifestations of cooperative efforts on the side of business. In 105 cases companies signed tolling agreements with OFAC. In 92 cases OFAC noticed that companies cooperated and promptly responded to the requests. Only eight companies failed to do so. In another 105 observations OFAC does not mention this, which means that it is not regarded as a mitigating factor (but it is not an aggravating one, either). On 43 occasions OFAC stated that companies had provided relevant information, and only in six cases OFAC officials specially pointed out that entities had failed to do so. In another 156 cases OFAC did not mention this factor either as mitigating or aggravating. These data show that companies tend to cooperate with OFAC during the investigation and that only a few of them fail to do so. The absence of OFAC assessments in many cases 
may mean that a person's behavior under investigation was at least not assessed as an aggravating factor.

The second group of variables includes measures taken by businesses to guarantee that violations will not occur in the future. In 132 cases out of 205 (64.3\%) companies took at least some measures to improve compliance with U.S. sanctions regimes. Only three entities failed to do so. In another 70 cases OFAC made no assessments, which means that this is not regarded as an aggravating factor. Settlement agreements contain information on specific measures to improve compliance. These data are incomplete. Apparently, OFAC has been more attentive to this information since 2018, and some data are available already for earlier cases. However, even the available data show some principal tendencies in companies' efforts to persuade OFAC that the risk of future violations is being treated seriously. In 32 cases compliance programs emerged from scratch as a remedial measure. In another 58 cases compliance programs were upgraded to a new level. Overall, there were 90 cases when compliance measures were devised or improved to meet OFAC requirements: eight companies initiated external audit of their compliance; seven companies conducted audit of their partner companies; four companies requested that their partners provide compliance procedures; 28 companies conducted personnel training; 13 companies installed new software to check transactions for sanctions risk; eight companies published manuals to educate their staff about sanctions; five companies fired employees responsible for sanctions violation; 15 companies hired additional compliance staff; and four companies increased sanctions compliance budgets. Although these data are incomplete and real remedial measures may be more extensive, they clearly indicate that remedial measures taken to avoid the risk of future violations is a regular and normal pattern of behavior.

The third kind of variables involves the history of violations. If OFAC enforcement actions against specific companies and individuals were ineffective, one would expect to observe cases emerging in the database several times. It is the policy of OFAC to regard the cases of new violations within five years after the previous one as an aggravating factor, while the absence of sanctions history for five years 
is considered a mitigating factor. According to OFAC data, in 162 cases sanctions history was not regarded as an aggravating factor and only in one case it was. The other 42 cases were not classified, which means that sanctions history is at least not treated as an aggravating factor. There are some companies which appear in the database several times; nine companies made settlement agreements with OFAC twice in ten years, but OFAC does not qualify this as an aggravating factor, taking into account the fact that the violations are more than five years apart. Repeated violations are rare.

In general, these data show that cooperation with OFAC changes the behavior of companies both during and after the investigation. Business tends to be more compliant with U.S. sanctions programs, as has been suggested by Hypothesis 2 .

\section{CONCLUSIONS AND DISCUSSION}

An attempt to study the efficiency of sanctions in terms of the "businesscentric" approach revealed a number of empirical observations. Firstly, there is no clear evidence that an intentional (rational) violation of sanctions is a widely spread pattern of conduct. At least this is true for 205 companies and individuals which faced an OFAC investigation in the past ten years. There are companies which violate rules willfully. However, much more violations result from reckless behavior. On many occasions recklessness is seemingly not the result of an initial strategy to decrease compliance costs, but rather comes from inaccuracy, unawareness, or poor compliance programs. Nonegregious violations prevail, which disproves the assumption about rationality as the main cause of violations. However, willful violations do occur and require a thorough case-study research. Apparently, the behavior of businesses which leads to violations differs from that of states. The latter may violate sanctions regulations for the sake of national or security interests, that is, they act more rationally than business which tends to act recklessly rather than willfully. These differences require further empirical verification.

Secondly, there is enough evidence that businesses significantly change their behavior during the investigation and afterwards. This is a 
regular pattern of behavior. It shows that OFAC measures are effective vis a vis business. Businesses' behavior is much different from that of states, as described in the literature. While targeted states often show commitment to the behavior which had led to sanctions, businesses rather show conformity and agreeableness. Non-conformism cases are exceptional.

These results, however, are still limited. First, the data on businesses cover only those of them which experienced OFAC investigations. There are far more companies that may change their intentions to violate the regulations, being threatened by an investigation or communicating with OFAC and other regulators in other ways. Also, the database presented in this study does not cover OFAC's SDNmeasures against violators, which could reveal different patterns of behavior.

There are some important methodological issues. The first and most acute one is the lack of information and a considerable amount of missing values. Future research could aim at a more sophisticated statistical analysis of the existing data. Also, it would be reasonable to study more profoundly the specific cases in qualitative terms.

\section{References}

Bapat, N.A., Heinrich, T., Kobayashi, Y. and Morgan, C., 2013. Determinants of Sanctions Effectiveness: Sensitivity Analysis Using New Data. International Interactions, 39 (1), pp. 79-98. DOI: 10.1080/03050629.2013.751298

Connolly, R., 2015. The Impact of EU Economic Sanctions on Russia. In: Dreyer, I. and Luengo-Cabrera, J. On Target? EU Sanctions as Security Policy Tools. Paris Institute for Security Studies, Report No. 25, pp. 29-38.

Connolly, R., 2018. Russia's Response to Sanctions. How Western Economic Statecraft Is Reshaping Political Economy in Russia. Cambridge: Cambridge University Press.

Cooper, Z. and Lorber, E., 2016. The Right Way to Sanction China. The National Interest, Vol. 142, March-April, pp. 36-42.

Crozet, M. and Hinz, J., 2016. Collateral Damage: The Impact of the Russia Sanctions on Sanctioning Countries Exports, CEPII Working Paper, June. 
Darsey, J. and Stulberg, A., 2019. Deaf Ears and the U.S.-EU-Russia Sanctions Tangle: Contending Strategic Discourses and Mutual Emboldenment. International Organizations Research Journal. Forthcoming.

Drezner, D., 1999. The Sanctions Paradox: Economic Statecraft and International Relations. New York: Cambridge University Press.

Drezner, D., 2015. Targeted Sanctions in a World of Global Finance. International Interactions, 41(4), pp. 755-764. DOI: 10.1080/03050629.2015.1041297

Early, B. and Preble, K., 2018. Enforcing Economic Sanctions: Analyzing How OFAC Punishes Violators of U.S. Sanctions. SSRN Papers [online]. Available at: $<$ https://papers.ssrn.com/sol3/papers.cfm?abstract_id=3306653> [Accessed 21 May 2019]

Economic Sanctions Enforcement Guidelines, 2009. Federal Register, 74 (2015), Monday, November 9. Available at: <https://www.treasury.gov/resource-center/ sanctions/Documents/fr74_57593.pdf > [Accessed 19 May 2019]

Fritsz, O, Christen, E., Sinabell, F., and Hinz, J., 2017. Russia's and the EU's Sanctions: Economic and Trade Effects, Compliance and the Way Forward. Brussels: Directorate-General for External Policies.

Giumelli, F., 2016. The Purposes of Targeted Sanctions. In: Beirsteker, T., Eckert, S. and Tourihno, M. (eds). Targeted Sanctions. The Impacts and Effectiveness of United Nations Action. New York: Cambridge University Press.

Graaf, T. van de, 2013. The "Oil Weapon" Reversed? Sanctions Against Iran and U.S.-EU Structural Power. Middle East Policy, 20(3), pp. 145-163.

Grauvogel J. and Soest Ch. Von, 2014. Claims to Legitimacy Count: Why Sanctions Fail to Instigate Democratization in Authoritarian Regimes. European Journal of Political Research, 53(4), pp. 635-653. DOI: 10.1111/1475-6765.12065

Hinz, J., 2017. The Cost of Sanctions: Estimating Lost Trade with Gravity. Kiel Working Paper, No. 2093, November.

Hufbauer, G., Shott, J., Elliott, K., 1990. Economic Sanctions Reconsidered: History and Current Policy. Second Edition. Washington DC: Peterson Institute for International Economics.

Hufbauer, G., Shott, J., Elliott, K., and Oegg, B., 2009. Economic Sanctions Reconsidered. Third Edition. Washington DC: Peterson Institute for International Economics.

Jaeger, M.D., 2018. Coercive Sanctions and International Conflicts. London and New York: Routledge. 
Jazairi, I., 2015. Report of the Special Rapporteur on the Negative Impact of Unilateral Coercive Measures on the Enjoyment of Human Rights. United Nations General Assembly Human Rights Council Thirty Session.

Jazairi, I., 2018. Report of the Special Rapporteur on the Negative Impact of Unilateral Coercive Measures on the Enjoyment of Human Rights on His Mission to the Syrian Arabic Republic. United Nations General Assembly Human Rights Council Thirty-Sixth Session.

Kaempfer, W. and Lowenberg, A.D., 2007. The Political Economy of Economic Sanctions. In: Sandler, T. and Hartley, K. (eds.) Handbook of Defense Economics, Vol. 2, Amsterdam: Elsevier.

Kholodilin, K., and Netsunaev, A., 2016. Crimea and Punishment: The Impact of Sanctions on Russian and European Economies. Berlin: German Institute of Economic Research, April 11.

Kholodilin, K and Netsunaev, A., 2017 Crimea and Punishment: The Impact of Sanctions on Russian and European Economies. Eesti Pank Working Papers, No. 5.

Kim, H., 2014 Stifled Growth and Added Suffering. Tensions Inherent in Sanctions Policies against North Korea. Critical Asian Studies, 46(1), pp. 91112.

Maloney, S., 2015. Sanctions and the Iranian Nuclear Deal: Silver Bullet or Blunt Object? Social Research, 82(4), pp. 887-911.

Marinov, N., Nili, Sh., 2014. Sanctions and Democracy. International Interactions, 41, pp. 765-778.

Moret, E., Giumelli, F. and Bastiat-Jarosz, D., 2017. Sanctions on Russia: Impacts and Economic Costs on the U.S. Geneva International Sanctions Network, March.

Nephew, R., 2018. The Art of Sanctions. A View from the Field. New York: Columbia University Press.

Neuenkirch, M. and Neumeier, F., 2015. The Impact of UN and U.S. Economic Sanctions on GDP Growth. European Journal of Political Economy, 40, pp. 110-125.

Pape, R.A., 1997. Why Economic Sanctions Do Not Work. International Security, 22(2), pp. 90-136.

Rosenberg, E., Goldman, Z., Drezner, D. and Solomon-Strauss, J., 2016. The New Tools of Economic Warfare. Effects and Effectiveness of Contemporary U.S. Financial Sanctions. Centre for a New American Security, April. 
Spadoni, P., 2010. Failed Sanctions: Why the U.S. Embargo Against Cuba Could Never Work. Gainesville: University Press of Florida.

Timofeev, I., 2019. Europe under the Fire from U.S. Secondary Sanctions. Valdai Club's Special Report for SPIEF-2019. Available at: <http://valdaiclub. com/a/reports/europe-under-fire/> [Accessed 25 May 2019]

Tourinho, M., 2015. Towards a World Police? The Implications of Individual Targeted Sanctions. International Affairs, 91(6), pp. 1399-1412.

Whang, T., 2011. Playing to the Home Crowd? Symbolic Use of Economic Sanctions in the United States. International Studies Quarterly, 55, pp. 787-801. Zarate, J., 2013. Treasury Wars. The Unleashing of a New Era of Financial Warfare. New York: Public Affairs. 